\title{
REFERENCES
}

Alexander, F. \& French, T. M. (1948). Studies in Psychosomatic Medicine. An Approach to the Cause and Treatment of Vegetative Disturbances. New York: Ronald.

Benedict, R. (1935). Patterns of Culture. London: Routledge.

Cannon, W. B. (1915). Bodily Changes in Pain, Hunger, Fear and Rage. New York: D. Appleton \& Co. Cobb, S. (1950). Emotions and Clinical Medicine. New York: W. W. Norton \& Co. Inc.

Jaques, E. (1948). Occup. Psychol. 32, 126.

Kennedy, J. C. (1953). Proc. Nutr. Soc. 12, 160.

MacLean, P. D. (1950). Psychosom. Med. Ir, 338.

Masserman, J. H. (1942). Amer. F. Psychiat. 98, 633.

Mead, M. (1939). From the South Seas. New York: Morrow.

Roberts, L. J. (1935). Nutrition Work with Children. Chicago, Ill.: University of Chicago Press.

Sheldon, W. H. \& Stevens, S. S. (1940). The Varieties of Human Physique. New York: Harper.

Sheldon, W. H. \& Stevens, S. S. (1942). Varieties of Temperament : a Psychology of Constitutional Differences. New York: Harper.

Walker, J. M. (1953). Proc. Nutr. Soc. 12, 157.

Wolf, S. \& Wolff, H. G. (1947). Human Gastric Function. An Experimental Study of a Man and his Stomach, and ed. New York: Oxford University Press.

\section{Psychiatric Implications of Disturbances of Eating and Nutrition}

\section{By W. M. Millar, Department of Mental Health, University of Aberdeen}

Disturbances of gastro-intestinal function and of nutrition are to be found as a cause of, a correlate with or a consequence to almost every form of psychiatric disorder, from transient neurosis to deep-seated and long-standing psychosis. The complex of processes that we call alimentary includes appetite, hunger, taste, smell, sucking, chewing, biting, salivation, digestion and elimination. Since these processes are all innate and vital, persisting throughout the life of the individual, we may expect them to enter into acquired processes of behaviour, to undergo complex elaboration and symbolization, to form a substrate of memory and to be superimposed upon many other activities of the human organism. Consequently it is not surprising to find that disorders of feeding are, as it were, first cousins to nervous disturbance.

This relationship is illustrated most simply in such conditions as vitamin deficiency, where the condition is easily recognized and treated. More commonly, however, the relationship is much more complex and obscure, the problem being concerned rather with the inner significance of feeding than with the quality of the food. This inner significance is both emotional and symbolic.

Of the more common varieties of eating disturbance encountered in psychiatric practice anorexia is perhaps the most frequent and is encountered in states of depression, in involutional melancholia, in some forms of psychoneurosis and behaviour disorders (especially in children) and in anorexia nervosa. Anorexia may take the form of loss of interest in food, desire for starvation and death, disgust and repulsion towards swallowing solids or fear that food will choke the bowels. Food fads in children and adults are of extraordinary variety, developing in some individuals into a way of life, such as vegetarianism. Dietetic rituals are encountered in the obsessive-compulsive neuroses. Food fears are seen in the phobic 
states. Globus hystericus, retching and vomiting are found in hysteria, Bulimia often occurs in those afflicted earlier or later with anorexia nervosa. Alcoholism and drug addiction may be regarded as extreme examples of disordered intake. Nail biting, nose picking and thumb sucking can be included in a similar way.

The relation may be illustrated by more complex examples. In catatonic states the patient refuses all food, requires tube-feeding and often exhibits a persistent pursing of the lips known as Schnauzkrampf. Schizophrenic patients sometimes exhibit gross feeding disturbances, eating their faeces and solid objects such as nails and stones, drinking urine and blood. Delusions connected with feeding are found in involutional melancholia: the patient imagines his bowels so full that he cannot eat any more food or that he has been starved and deprived of food or that he has been poisoned by food. Patients with anorexia sometimes entertain the phantasy that they have swallowed something to make them pregnant. Cannibalistic phantasies are frequently related by patients undergoing intensive psychotherapy.

The facts of clinical observation have been greatly enriched in recent years by contributions from the basic sciences-especially those of anatomy, physiology and psychology-and by other clinical disciplines, such as paediatrics and psychosomatic medicine.

Since the pioneer researches of Pavlov (I 927) and Cannon (1947) the relation of emotion to gastric function has been well established, although the precise quality of the emotional stresses involved and many of the intermediate steps in the causal chain remain obscure. The emotions of fear and rage have been given special prominence in this connexion. 'The production of 'sham rage' in animals indicated that the thalamus might be the 'seat of the emotions', though later work suggests that the thalamus mediates but does not 'experience' emotion. MacLean (1949) refers to the comparatively unknown work on the rhinencephalon by Papez, who observed that, though the connexions between the hypothalamus (the head ganglion of the autonomic nervous system) and the cerebral cortex are meagre, those with the hippocampus are abundant. The fornix, for instance, has the thickness of a pencil. He considered that the old brain, far from being a vestigial olfactory remnant whose functions had now been taken over by the new brain, has in the human continued its own evolutionary development. The hippocampus, the anterior thalamic nuclei, the gyrus cynguli and the hypothalamus constitute, in his view, 'a harmonious mechanism which may elaborate the functions of the central emotion as well as participate in emotional expression'. 'This being so, it is thought that the rhinencephalon is capable of a crude affective experience that is symbolic, nonverbal and undiscriminating. Further, since the interconnexions between rhinencephalon and cerebral cortex are not well established, it is possible in the same individual for complex discriminating intellectual functions to be carried out, while at the same time irrational, inexplicable and incommunicable emotions are being experienced. It is of particular interest to psychiatrists to learn that oral, olfactory and sexual representations in the hippocampus are to be found closely contiguous and interrelated. We can thus understand more readily how it comes 
about that smell plays so prominent a part both in eating and in sexual activity; and that oral activity, such as kissing, is likewise related. It is to be hoped that further research in this field will be stimulated and that more light will be shed on these and other clinical paradoxes.

The work of Dunbar (1935, I943) has been notable for its collation of the world literature on the so-called psychosomatic disorders, and it is chiefly from this field of clinical research that we have derived working concepts relating emotions to visceral disturbances. However, despite the painstaking nature of most psychosomatic investigations-characterized by exhaustive anamneses occupying many hours in each case-the impression of vagueness is conveyed, with few practical therapeutic results. Classification of the disorders and correlation of these with personality types have remained for the most part unprofitable. This may, to some extent, be due to the fact that current personology, largely derived as it is from academic psychology, gives undue weight to cognitive (that is, higher cerebral) functions, at the expense of the conative and affective (perhaps rhinencephalic) functions. Many investigators, however, have become aware of this criticism and have directed their investigations towards the nature of the life situations encountered by the individual as explanatory of the emotional reaction and its attendant visceral disorder. Wolf \& Wolff (1947) in their study of the now famous case of Tom (whose stomach mucosa was visible through a fistula and who has co-operated in these investigations over a number of years) have shown how changes in gastric secretion, acidity, motility and hyperaemia were correlated with certain stressful events in his life. Hinkle \& Wolf (I950) have demonstrated analogous correlations in diabetes mellitus, changes in glucose, ketone and water metabolism all occurring in response to certain types of stress. One of the most ingenious investigations of this kind-and one with considerable importance for the psychiatrist--is described by Mirsky, Kaplan \& Broh-Kahn (1950). Employing uropepsin excretion as an index of gastric activity, they compared the fluctuations thus inferred with the day-to-day events of a number of subjects undergoing daily intensive psychotherapy. Two of their most interesting findings were, first, that only a certain type of stress gave rise to increased gastric activity, namely oral-dependent conflicts related to the mother or a mother substitute, and secondly that many clearly important events in the lives of these subjects passed with no conscious awareness of stress or conflict, yet. were associated with marked gastric activity. This bears out the clinical observation in psychiatry that the communications of a patient as to his experienced stresses must not be taken at their face value and that, for instance, the common-sense notion of 'worry' as an aetiological agent must be abandoned. Put in another way it means that the resistances of the patient to the establishing of the true situation (so often guilt-laden) must first of all be overcome. Furthermore it means that the doctor's own resistance to the facts of the case must also be tackled.

The discoveries of psycho-analysis and modern dynamic psychology have without doubt stimulated thought and research in this more than in any other psychiatric field. The method of free-association has brought to light information 
inaccessible to any but the poets and the seers. The discovery of unconscious processes has rendered untenable the classic view of psychology that mind is only conscious, immaterial and abstract. The emphasis upon instinctual processes made it theoretically possible to consider a unitary biological theory of mind, placed firmly within nature and subject to the same laws as the body. It is thus unnecessary to refer to the actual eating of food as a 'physical' phenomenon and, say, the memory of food or the fear of eating as 'psychological' phenomena. All are biological phenomena. The genetic approach of psycho-analysis, stressing the importance of maturation as a determinant of personality, is another major contribution. The phasic development of the personality has been described, and the phenomena of fixation and regression have come to be recognized as growth disturbances fundamental in producing psychotic and neurotic illness. Of the developmental phases the first and most critical for development is the oral, extending over the first months of life. It is characterized by three modes of experience: hunger, with mounting tension; the process of incorporation; the re-establishment of equilibrium (homeostasis) with relaxation and sleep. The subjective experiences of this phase and the relationships involved undergo considerable elaboration and symbolization and, with further development, differentiation. Disturbances occurring during this phase give rise to their own characteristic reactions, elaborations and symbolizations, perpetuated in memory. Stresses encountered in later life produce a reactivation of these early disturbances related to this phase. This is the process referred to as regression.

The nature of the elaboration and symbolization already mentioned may be understood if we consider the mode of experience of incorporation. Incorporation for the infant means not only the assimilation of milk from the breast but also the devouring of the breast. Indeed, any relationship between the child and the environment is characterized by this same process, as, for example, the habit of introducing into the mouth every object that can be handled. Fairbairn ( $195^{2}$ ), whose theory of object relations has aroused considerable interest in psychiatry, regards incorporation and the establishment of 'internalized objects' as perhaps the central process in personality development. Incorporation is therefore concerned not only with the intake of food but with the assimilation of all objects in the environment, conceived as symbolizations and elaborations of food.

Though it would be premature at this stage in our knowledge of the mind-body relationship to employ a common language and a common set of concepts to describe both physical and psychological processes, clinical and experimental evidence suggests that this is a reasonable expectation. When we consider the central position of alimentation in determining the growth and structure of the body and of the total personality, it is likely that this will prove to be the most rewarding field for further study, if we are to achieve our aim of a unitary conception of human nature.

\section{REFERENCES}

Cannon, W. B. (1947). The Wisdom of the Body, revised ed. London: Kegan Paul.

Dunbar, H. F. (1935). Emotions and Bodily Changes. A Survey of the Literature on Pyschosomatic Interrelationships, 1910-33. New York: Columbia University Press. 
Dunbar, M. F. (1943). Psychosomatic Diagnosis, Ist ed. New York: Hoebner.

Fairbairn, W. R. D. (1952). Psychoanalytical Studies of the Personality, Ist ed. London: Tavistock. Hinkle, L. E. \& Wolf, S. (1950). In Life Stress and Bodily Disease, p. 338. [H. G. Wolff, S. G. Wolf and C. C. Hare, editors.] New York: Williams and Wilkins Co.

Maclean, P. (1949). Psychosom. Med. r1, 338.

Mirsky, A., Kaplan, S. \& Broh-Kahn, R. (1950). In Life Stress and Bodily Disease, p. 628. [H. G. Wolff, S. G. Wolf and C. C. Hare, editors.] New York: Williams and Wilkins Co.

Pavlov, I, P. (1927), Conditioned Reflexes, ist ed. Oxford: University Press.

Wolf, S. \& Wolff, H. G. (1947). Human Gastric Function. An Experimental Study of a Man and his Stomach, and ed. Oxford: University Press.

\section{Peptic Ulceration}

\section{By C. F. W. IllingworTh, Department of Surgery, University of Glasgow}

It is the modern fashion to speak of peptic ulcer as a psychosomatic disorder, by which we mean that psychological disturbances play a considerable part in the origin of the disease. It is, however, now universally accepted that the actual development of peptic ulcer is due to the erosive action of the acid gastric juice upon an area of mucous membrane that may be presumed to have become devitalized in some way and thus to have lost its normal powers of resistance to its own enzymes. Psychological disturbances may possibly influence this process by increasing the volume of acidity of the gastric juice or by reducing the resistance of the mucous membrane or perhaps by both. In examining the significance of psychological factors in peptic ulcer it is therefore necessary first to study the extent to which psychological stimuli can influence gastric acidity and the condition of the gastric and duodenal mucous membranes.

In the second place, as some people develop ulcers and others do not, we must try to discover whether a predisposition to ulcer is related to any particular type of psychological make-up or temperament.

'Thirdly, since it is claimed that ulcer may be due to the direct effect of acute psychological stresses, such as acute worries or anxieties or severe emotional experience, we must attempt to find out the extent to which the onset of an ulcer or the development of a complication is preceded by such a stress.

\section{Influence of emotional factors on gastric secretion and motility}

Common experience allows ready acceptance of the view that psychological states can influence the gastric functions. Well known, for example, are the anorexia and nausea that afflict examination candidates and timid lecturers, the empty feeling in the epigastrium in situations of danger, the vomiting as a response to disgusting sights. Indeed the word disgust itself is founded on emotional aversion to the sight of food.

Scientific studies give much confirmatory evidence. Pavlov's (I gro) observations on the appetite juice showed clearly that the acid secretion is responsive to psychic stimuli, and more recent workers have proved that motor and circulatory changes are also brought about in the same way. 